\title{
Motives to Assist and Reasons to Assist: the Case of Global Poverty
}

\author{
SIMON KELLER \\ Victoria University of Wellington
}

\begin{abstract}
The principle of assistance says that the global rich should help the global poor because they are able to do so, and at little cost. The principle of contribution says that the rich should help the poor because the rich are partly to blame for the plight of the poor. This paper explores the relationship between the two principles and offers support for one version of the principle of assistance. The principle of assistance is most plausible, the paper argues, when formulated so as to identify obligations that arise from the needs of particular identifiable members of the global poor, not from impersonal rules or values. Under that formulation, the principle can explain why knowledge of the circumstances faced by individual members of the global poor can have such a marked effect upon the willingness of the global rich to provide help, and can offer a better grounded motivational basis for helping the global poor. These are real advantages, the paper argues, and ones that cannot be matched by stories that focus upon the ways in which the global rich contribute to global poverty.
\end{abstract}

\section{THE GLOBAL RICH AND THE GLOBAL POOR}

The world's wealthier people are much, much richer than the world's poorer people. The size of the inequality is difficult to comprehend, but here are some credible estimates: $85 \%$ of the world's wealth is held by го\% of its population, the poorest $50 \%$ of the world's population holds $1 \%$ of its wealth, and the richest $20 \%$ of the world's population consumes $77 \%$ of its material goods (Shah 20II). Anyone reading 
this paper is probably, in global terms, rich. "We" are the global rich and "they" are the global poor.

That the global poor are much poorer than us does not mean that they are poor absolutely, and it does not mean that they live bad lives. Many of the global poor, surely, live happier and more fulfilled lives than many of us. But many of the global poor are absolutely poor and do suffer profoundly as a result. Again, no brief description can be adequate, but here, again, are some credible estimates: 22,000 people die every day due to poverty-related causes, I.4 billion people live on less than US $\$$ I.25 per day, I.8 million children die each year due to diarrhea, and 400 million children lack access to safe water (Shah 20II). Poverty brings not only suffering but also vulnerability. Many of the global poor are unable to exercise meaningful control over the directions of their lives, and many are subject to economic and personal exploitation (O’Neill 2007).

The misfortune of the global poor is not unrelated to the fortune of the global rich, and it is plausible - though not uncontroversial — to say that the global rich are partly responsible for the plight of the global poor. Entrenched global poverty can be partly attributed, arguably, to an ongoing history of colonial, military, and financial interventions of rich countries into poor countries. We participate with the global poor in an integrated global economy whose structures and guiding institutions, arguably, are largely mandated by rich countries and ensure that global poverty is perpetuated (Pogge 2007, pp. 634-638; Singer 2009, pp. 30-35).

It is also plausible - though not, again, uncontroversial — to say that it is within our power to improve the lives of the global poor, and to do so at relatively small cost to ourselves. Compared with the amount of money spent by a person like you and me every day on luxuries, it does not cost very much to provide a poor person in a poor country with essential medicines, nutrition, and shelter, and there exist prominent charities that do a good job of transferring money from the global rich to the global poor (Singer 1972, p. 232; Singer 2009, pp. I5-I9 and ch. 6). We may also help the global poor indirectly by donating money to political campaigns, pressuring our governments and corporations, and changing our habits as consumers, to give just a few examples (Singer 1972, p. 240; Singer 2009, ch. 7). 


\section{HELPING THE GLOBAL POOR: REASONS VERSUS MOTIVES}

Supposing that the claims just mentioned are all correct-we are much richer than the global poor, many of them are badly off in absolute terms, their poverty is partly our fault, and we are in a position to help them-it is very plausible to think that we have a moral reason to help the global poor: that morally, all else equal, we should do something to help. But what is the nature of that moral reason, exactly? Here are two possible stories (Barry and Overland 20I2, pp. 869-870; Barry and Overland 2013).

On one story, we should help the global poor because they are in need and we can help them, and at a relatively insignificant cost to ourselves. Our moral reason to help the global poor, runs the story, arises just from the facts about their plight and our ability to help alleviate it. This story rests upon a moral principle that we can call "the principle of assistance." The principle of assistance says that we should help the global poor because we can, and at little sacrifice (Singer 1972; Cullity 2004; Singer 2009).

On another story, it is a crucial additional fact that we bear blame for the plight of the global poor. Our moral reason to help the global poor, runs this second story, is that we owe them restitution for the harms that we-the global rich-have done them. The principle that lies behind this story can be called "the principle of contribution." The principle of contribution says that we should help the global poor because we have contributed to their poverty (Pogge 2002, pp. II-20; Pogge 2007, pp. 633-634; Pogge 2010, pp. 20-15; Risse 2012, pp. I13-II8).

Each story is plausible on the surface, and the principle of assistance and the principle of contribution are not incompatible. The two principles, as I have expressed them, are concerned only with moral reasons to relieve global poverty, but they each reflect something compelling about moral reasons to help others more generally. If you see a child who is in distress after falling off her bike, and if you can easily give her help, then you should help her-and you have extra reason to help her if it was you who caused her fall.

Many of us find it very natural, then, to think that we have strong moral reason, of one kind or another, to help poor people in other parts of the world. But those of us who believe that we have such a reason are unlikely to believe that we do a very good job of acting on it. Our governments do not do much, really, to relieve global poverty; the world's richest countries give around $0.29 \%$ of their gross national income in aid to impoverished countries (Organisation for Economic Co-operation 
and Development, 2015). As individuals, many of us do nothing, and many of us do hardly anything. There are few who would accept the principle of assistance or the principle of contribution while also believing that the obligations of the global rich to the global poor are being fully discharged.

It is not just that we do not do enough to help the global poor. It is also that our patterns of helping the global poor do not appear to respond reliably to our reasons to help them. The global poor are always there and always in need of help, but we are more likely to be generous in response to identifiable, delimited individuals or events than in response to ongoing global poverty. We are more likely to give to a relief effort to help victims of a war, an earthquake, or a tsunami than to give to efforts to help people whose poverty is caused by long-term systemic factors. We are more likely to give if we take ourselves to be sponsoring a particular impoverished child, rather than to be one contributor to an effort to help many impoverished people. We are moved more by images and stories of particular poor people than by information about the overall problem of global poverty (Singer 2009, pp. 48-56). In all of these respects, our tendencies to help the global poor seem insufficiently responsive to the truly morally weighty features of the phenomenon of global poverty: its sheer size and its entrenchment. When it comes to helping the global poor, we may say, our reasons are not matched by our motives.

\section{THIS PAPER}

That is my description of the basic facts, including the basic moral facts, of the relationship between the global rich and the global poor. As mentioned, my description is open to dispute at several points, but still, it is plausible and widely believed and it sets the scene for this paper. My goal in this paper is to defend a version of the principle of assistance: one that I call the "individuals-based" principle of assistance, and that grounds our moral reasons for helping the global poor in considerations of particular individual members of the global poor. The principle of contribution, for all I say, may also yield moral reasons to help relieve global poverty, and other versions of the principle of assistance may do so too; the various stories are not, after all, incompatible. But I want to show that only the individuals-based principle of assistance can explain certain crucial facts about our motives to help the global poor, and that this is a reason to think the principle correct. If I am right, then the individuals- 
based principle of assistance must be a big part of the truth about our moral reasons to help relieve global poverty.

My case for the individuals-based principle of assistance draws conclusions about reasons to help the global poor based on some claims about our motives for helping the global poor. It is one thing to talk about our reasons and another to talk about our motives. But, I want to show, these topics are linked. Different stories about our reasons yield different claims about what knowledge we have of our reasons, and our motives are likely to be different depending upon how much we know about our reasons. More specifically, I shall try to show that the individuals-based principle of assistance predicts that we in our present situation lack full knowledge of our moral reasons to help the global poor, and that it follows that our motives for helping the global poor are likely to be unreliable and sporadic, in much the ways we in fact find them to be. That is a reason for thinking that we take our reasons to be those posited by the individuals-based principle of assistance, and that, I shall go on to argue, is a reason for thinking that that principle is correct.

I should be clear about how I am using some terms. A "reason" to act, as I use the term, is a consideration that counts in favor of an action. By "counts in favor" I mean "really counts in favor"; on my way of talking, a "bad reason" is no reason at all. A "moral reason" is a moral consideration that counts in favor of a certain action. When I offer something as a moral reason for you to do something, I mean to explain why you morally should do it, all other things equal. That playing computer games all afternoon would be fun, for example, might be a reason to play computer games all afternoon, without being a moral reason.

A "motive" for action, as I use the term, is whatever moves a person towards performing an action. (Note that you might have a motive to perform an act but not in fact perform the act; you might try to perform the act and fail, or your motive might be outweighed by a different motive.) Sometimes, what moves you to perform an action might be a consideration that counts in favor of the action, and is hence also a reason to act: you might be motivated to brush your teeth by the thought that brushing your teeth helps avoid tooth decay, and the fact that brushing your teeth helps avoid tooth decay may be a consideration that in fact favors your brushing your teeth. Sometimes, your motive may be a consideration that does not in fact count as a reason: you might be moved to brush your teeth by the thought that brushing your teeth helps save the rainforests. And sometimes, your motive may involve no consid- 
eration at all: you might be moved to brush your teeth by a bare urge or impulse or habit.

The paper's argument rests upon distinctions between different versions of the principle of assistance and the principle of contribution, and a conviction that making the distinctions is worthwhile. So I will start by saying how the principle of assistance and principle of contribution might be more precisely expressed, and why the choice between them, in their various forms, matters.

\section{ASSISTANCE AND CONTRIBUTION}

The principle of assistance says that we should help the global poor because they need our help and we can provide it, and at little sacrifice to ourselves. The principle of contribution says that we should help the global poor because we have contributed to their poverty. There are various strategies through which either principle could be connected with a wider claim about obligations to help others. It is an open question on the principle of assistance, for example, whether we have obligations to help the global poor even when doing so does require significant sacrifice, and it is an open question whether we have obligations to help anyone-poor or not-whom we could help with little sacrifice. Similarly, an advocate of the principle of contribution may say that we are obliged to give restitution for all harm to which we contribute, or only for harm to which we wrongly contribute, or whatever else.

Even as stated, though, the two principles posit reasons that apply in different cases and that sometimes pull in different directions. There may be people who live in severe poverty and whom we are able to help, but whose poverty cannot be blamed on the global rich; in such cases, the principle of assistance but not the principle of contribution posits reasons to help. There may be impoverished people whose poverty is not severe, by world standards, and whom we could only help with difficulty, but whose poverty is clearly our fault; in a case like this, the principle of contribution would appear to offer a reason to help, but the principle of assistance may not.

There may also be cases in which the two principles yield different claims about whom it is most important to help, or about whom we should help first. Depending upon exactly how they are expressed, the principle of assistance is likely to recommend that we be guided by the goal of giving as much help as we can to those who need it most, while the principle of contribution is likely to recommend that we be 
guided by the goal of giving compensation to those to whom we have caused the greatest harm. These goals can conflict. Sometimes we may have to choose, for example, whether to help someone who is in greater poverty or someone for whose poverty we carry greater blame.

It matters for practical purposes whether we accept one of the principles and dismiss the other, and if we accept that there is truth in both principles, then it matters how we weigh them against each other. It also matters, in a number of respects, how exactly the two principles are formulated. Let me briefly mention two questions of formulation faced by the principles, before discussing at some length a third.

First, the principles need to say what counts as helping the global poor. The principle of assistance could tell us to make the global poor happier, for example, or to satisfy their basic material needs, or to make them less exploited, or to ensure that they have greater opportunities. The principle of contribution could tell us to compensate the poor with money, for example, or with whatever would best address their lack of happiness, or it could say that the global poor are now our responsibility in some broader sense.

Second, the principles need to say, at various points, whether they are speaking of groups or of individuals. To see how this makes a difference, imagine the following case.

Suppose that the philosophers at a university have an obligation to provide morning tea for the whole faculty. This will be an obligation held by the philosophers as a group. It does not matter which particular philosophers provide the morning tea, and it does not matter if some philosophers take no part in its provision. So long as the morning tea is provided by someone acting on behalf of the philosophers, the obligation is discharged. Our obligation to help the global poor could, like this one, be a group obligation. It could require that something be done on the part of the global rich, considered as a group, whether any particular member of the global rich contributes or not.

The philosophers at the university may also have an obligation to attend a staff meeting. This obligation will not be held by the philosophers considered as group, but will instead fall on each philosopher considered separately: each philosopher is obliged to attend the meeting. There are then really several obligations to attend the meeting-one for each philosopher-and those obligations cannot be discharged just through some philosophers acting in the name of all the philosophers. If our obligation to help the global poor is like the philosophers' obligation to attend a staff 
meeting, then it is an obligation that falls separately upon each of us. To speak of the obligation of the global rich would then be to speak, really, of many obligations-one for each member of the global rich-and it would not be possible for all our obligations to the global poor to be discharged just through the acts of some rich people acting on behalf of all of us.

Just as an obligation can fall collectively upon a group or separately upon each member of a group, an obligation can be held towards a group or separately towards each member of a group. The obligation of the global rich could be an obligation to improve the lot of the global poor, considered as a class. Or it could be an obligation held towards each person within that class, so that there are really many obligations on the part of the global rich, one towards each member of the global poor.

The same goes for talk about the ability of the global rich to help the global poor. Are we talking about what could be done by the global rich, considered as a class, or about what could be done by the various individual rich people? Are we talking about an ability to help the global poor, construed as a group, or about various abilities to help various particular members of the global poor?

And, the same goes for talk about the contribution made by the global rich to the plight of the global poor. Are we talking about a contribution to the existence of a class of poor people, or are we talking about a contribution to the poverty of particular poor individuals? Are we talking about the contribution made by the global rich, considered collectively, or about the individual contributions of various individual rich people?

Depending upon how the principles answer these questions, they will tell different stories about where the obligations to help reduce global poverty fall, where they come from, and what it would take for them to be met. How the principles answer these questions also makes a difference to how plausible the principles are, and to how they can be compared and contrasted with each other-and also, I will say later, to how the reasons posited in the principles might be expressed in our motives.

\section{UTILITARIANISM AND THE PRINCIPLE OF ASSISTANCE}

I now want to spend some time discussing a third question faced by the principles. The question is about what kind of consideration grounds our moral reason to help the global poor, and whether that consideration is concerned with certain 
individual people, or instead with certain values. I will start by explaining how the question arises for a utilitarian approach to the principle of assistance.

Utilitarianism, as I shall speak of it, says that the right act to perform under any circumstances is the one that produces the greatest possible balance of happiness over unhappiness. (This is one form of utilitarianism. There are others, but for the sake of illustration this one will do.) Utilitarianism, in conjunction with the facts about global poverty, leads quickly to a version of the principle of assistance. There are acts we can perform that will involve relatively small sacrifices in happiness for us while bringing about relatively large increases in happiness for the global poor, so by helping the global poor we can increase the overall balance of happiness over unhappiness. But consider two different stories about how you might come to utilitarianism in the first place.

A first story about how to get to utilitarianism begins with some claims about value. Happiness, you might think, is a good thing: it is good to be happy, and the world is better if it contains more happiness. And unhappiness, you might think, is a bad thing: it is bad to be unhappy, and the more unhappiness a world contains, the worse it is. You might think, furthermore, that where things apart from happiness and unhappiness are good or bad, their goodness and badness can be understood by reference to their contributions to happiness and unhappiness. Happiness and unhappiness, you might then conclude, are the only two things that have foundational value or disvalue, or that contribute in their own rights to making the world better and worse.

What will that tell you about rightness and wrongness? Well, you might accept the suggestion that people act rightly when they make the world better and wrongly when they make the world worse. If that is what you think, then you will go on to conclude that morally right acts are those that produce as much happiness and as little unhappiness as possible. And so you will have arrived at utilitarianism.

That story is condensed and stylized. The important point, for my purposes, is that it identifies a route to utilitarianism from a commitment about impersonal value. There is no mention within the story of the fact that the good and bad things-happiness and unhappiness - are always manifested in individuals. Only subsequent to the story, once we start working out what we actually need to do in order to maximize the balance of happiness over unhappiness, does it become relevant that we can only change facts about happiness and unhappiness by making a difference to the levels of happiness enjoyed by particular individuals. As far as the story goes, it is not im- 
portant whether all the happiness and unhappiness is concentrated in a single individual, or how happiness and unhappiness are distributed across various individuals, or how many individuals there are. The concern in the first instance is with happiness and unhappiness, not with the individuals in whom happiness and unhappiness are to be found.

It is when we ground utilitarianism in this kind of story that we come most naturally to the thought that for utilitarianism, individuals are moral "buckets." For moral purposes, runs the thought, individuals matter only because they are receptacles in which happiness and unhappiness can be contained. Some expressions of the well-known objection that utilitarianism "does not take seriously the distinction between persons" are best understood as complaints about this utilitarian thought (Rawls I972, p. 27). Utilitarianism misses something morally important, according to such complaints, because it addresses persons merely as contributors to impersonal value, not as separate individuals with their own lives to live.

Following this first story about how to argue towards utilitarianism, the principle of assistance will appear as a special case of a general injunction to distribute resources in ways that generate the most overall value. Our moral reason to help the global poor, on the story, is that by helping the global poor we can make it the case that the world contains more of the foundational good and less of the foundational bad. This is "values-based" utilitarianism, similar to what others call "teleological" utilitarianism (Kymlicka 2002, pp. 32-37). It supports a "values-based" principle of assistance. The reason revealed by the principle of assistance is a reason to respond properly to the value of happiness and the disvalue of unhappiness.

Now for the second story about how to argue towards utilitarianism. Instead of beginning with some claims about value, suppose that you begin by thinking about the individuals for which you have moral concern. To the extent to which you are morally motivated, which individuals seem to you to matter? You might answer by saying that the morally considerable individuals are all those who are sentient, or who have subjective experiences, or who have a point of view, or who can be better or worse off, or who can be happy or unhappy-where it is plausible to think that an individual who has one of these features has all of them. Humans and sentient nonhuman animals matter morally, you might think, but trees and bricks do not.

Thinking now about some particular morally considerable individual, ask what sort of treatment it merits. What is the right way to treat an individual that has its own point of view? There are many possible answers, but one of them is that the right 
way to care about a morally considerable individual is to care about its happiness. Many individuals in the world merit moral concern, on this answer, and the right kind of moral concern, as addressed to any one of those individuals, is a desire that the individual enjoy happiness rather than suffering unhappiness.

For each individual, you may then think, we have a moral reason to do things that contribute to its happiness and detract from its unhappiness. Such reasons, you might conclude, are the most fundamental moral reasons there are.

Such reasons, however, conflict. We cannot always make everyone happy. Sometimes, the act that will maximize one person's happiness will set back the happiness of another; sometimes, we have no choice but to discriminate between the demands made by different morally considerable individuals. So, we need a rule that tells us what to do when we cannot do the right thing by everyone. There are many rules we could conceivably adopt, but one of them is this: when you cannot make every individual happy, do whatever produces the most happiness and least unhappiness overall. It is unfortunate that we sometimes need to sacrifice the happiness of some individuals to secure the happiness of others, but when it must be done-you might think - the way to do it is to see which individuals have what quantities of happiness at stake, and then to choose options yielding greater quantities of overall happiness over those yielding smaller quantities.

And that is the second story, again condensed and stylized, about how to arrive at a utilitarian criterion of right action. What matters for present purposes is that the story gets to utilitarianism from a concern with individuals. Unlike the first story about how to get to utilitarianism, this second story does not explicitly call upon judgments about impersonal value. Unlike the first story, this second story passes through a point in the argument at which it would be possible, having identified the morally considerable individuals, to say that we should be concerned not with their happiness, but instead with-say-their preferences, moral flourishing, or levels of autonomy; and it passes through a point at which it would be possible to reject the maximization principle in favor of a principle that tells us-say-to spread happiness equally, or to maximize the level of happiness enjoyed by the person who has least, or to refuse to make comparisons between the happiness levels of individuals at all.

Compared with the first story about how to argue towards utilitarianism, it is more difficult to accuse this second story of failing to take seriously the distinction between persons. The command to maximize the balance of happiness over unhappiness, on this second story, is offered as a way of coping with the fact that different 
persons have different and competing points of view. It is never imagined that individuals are not separate, or that they matter only for their contributions to an overall impersonal value. Utilitarianism arrived at through this line of thinking can be called "individuals-based" utilitarianism; it has affinities with what others have described as utilitarianism based on "equal consideration of interests" (Kymlicka 2002, pp. 32-37).

Like the first story, this second story about how to get to utilitarianism yields a version of the principle of assistance, but the line of thought that takes us there is different. The poor people of the world are morally considerable individuals, just like us, so we ought to make them happy rather than unhappy. To contribute to their happiness, we need to make sacrifices in our own levels of happiness, and that is unfortunate. But, looking at the plights of those individuals, it is clear that the stakes for them are far greater than are the stakes for us. So, if we have a proper moral concern for those individuals, then we will see that we ought to make the relatively small sacrifices in our levels of happiness required to secure relatively large increases in theirs. Our reason to help the global poor is a reason to respond properly to the morally considerable individuals that make up the global poor. It is in this sense that we have arrived at an "individuals-based" principle of assistance.

\section{TWO VERSIONS OF THE PRINCIPLE OF ASSISTANCE}

The two stories about how to get to utilitarianism illustrate the distinction between the values-based and the individuals-based principle of assistance, but the distinction does not rest on anything special about utilitarianism.

Speaking generally, the values-based principle of assistance says that our moral reason to help the global poor is a reason to respond properly to certain values. Values-based utilitarianism, as I have imagined it, says that the values are happiness and unhappiness and the proper response is to maximize one and minimize the other, but other stories could be told. There can be other claims about which are the relevant values, and there can be other claims about what counts as a proper response to them.

An example of a non-utilitarian values-based principle of assistance can be found in Onora O'Neill's Kantian account of our obligations to the global poor (O’Neill 2007, see especially pp. 558-560). O'Neill endorses a version of the principle of assistance, saying that the fact that people are in poverty in itself provides us with an (imperfect) duty to do something to help them if we can. The consideration that 
explains the existence of that duty is, for O'Neill, the value of autonomy: the plight of the global poor is morally significant because poverty undermines the preconditions of autonomy. The correct response to the value of autonomy, on O'Neill's view, is not to maximize it, but rather to live a life that honors it. For O'Neill, to honor the value of autonomy is, among other things, to recognize that humans need the support of others to achieve full autonomy, and hence to do something, here and there, to alleviate conditions that make autonomy more difficult to achieve.

On the individuals-based principle of assistance, our moral reason to help the global poor is a reason to respond properly to the various people who make up the global poor. The individuals-based version of utilitarianism, as I present it, says that the right response to those people is to try to increase their happiness, but, again, there are other stories to tell: other possible stories about what treatment people merit, and about how to make discriminations when not everyone can get the treatment they would ideally receive.

An example of a non-utilitarian individuals-based principle of assistance might be found in the view that our reasons to assist the global poor are generated by their natural positive rights. It might be held, for example, that every person has a right to have her basic needs met, if the resources required to meet those needs exist (Ashford 2007). The way to respond to any morally considerable individual, it might be held, is to respect her rights, and so for each person within the global poor we have a reason to do what we can to alleviate that person's poverty.

It is also possible to tell a Kantian story, different from O'Neill's, that generates an individuals-based principle of assistance. We could say that each person, as a rational being with the capacity for autonomy, demands in her own right whatever she needs in order to manifest genuine autonomy. That demand, we could say, then falls upon any person who could help make it the case that autonomy, for her, is achievable. As things are, many of the global poor face conditions that compromise their autonomy, and the global rich could alleviate those conditions at little sacrifice. So, we could conclude, our moral reason to help the global poor can be broken down into many different reasons to help: one for each of the rational individuals whose ability to live autonomously is compromised by her poverty. 


\section{TWO VERSIONS OF THE PRINCIPLE OF CONTRIBUTION}

There is a distinction between the values-based and the individuals-based principle of assistance. We can make the same distinction between different versions of the principle of contribution, though doing so is more difficult and perhaps less natural. Here is how it could work.

As a first possible route towards the principle of contribution, you could begin with a concern for particular individuals within the global poor whose poverty is partly caused by actions of the global rich. Then you could make the judgment that each of those particular individuals is owed restitution for the harms she has suffered, and hence that the global rich should help the global poor. The basic moral relationship behind the principle of contribution, so understood, is between the global rich, on one hand, and many members of the global poor considered separately, on the other. For each impoverished person whose poverty is partly caused by the actions of the global rich, there is a moral reason for the global rich to help that person. So this approach to the principle of contribution is individuals-based. Our moral reason to help the global poor, on this approach, really comes down to our many moral relationships with the many members of the global poor whom we have harmed, and to the many reasons that emerge from those many relationships.

As a second possibility, you could begin with the thought that the global rich, through their actions toward the global poor, have failed to respond properly to certain values. You might say, for example, that happiness is valuable and the global rich have, through their treatment of the global poor, spread unhappiness; or you might say that autonomy is valuable and the global rich have, through their treatment of the global poor, undermined autonomy. Where someone has failed to respond properly to a certain value, you might add, she can become obliged to make amends by doing what she can to restore the value where it was damaged. We might show proper respect for the value of happiness, for example, by trying to restore the happiness of the people whom our past actions have made less happy; and we might show proper respect for the value of autonomy by helping those whose autonomy we have damaged in the past to enjoy greater autonomy in the future. You might go on to say that we have contributed to the unhappiness and undermined the autonomy of the global poor, and so we now have a special responsibility to help the global poor, as an expression of respect for the values of happiness and autonomy. If that is how 
you explain our moral reasons to help the global poor, then you have a values-based version of the principle of contribution.

I hope that the distinction between the values-based and individuals-based principles is now reasonably clear. It may become clearer as I explain the use to which I want to put it. First, though, I want to turn to a different topic: our knowledge of reasons, and how that knowledge is reflected in our motives.

\section{KNOWLEDGE OF REASONS}

It is possible to know that you have a reason to do something without knowing what that reason is. To put it another way, it is possible to know about the existence of a reason while lacking knowlege about its nature (Keller 2013, pp. 87-90).

Suppose you get some medicine from the doctor, and she tells you that you must take it with food. If I ask you, "Should you take the medicine with food?" then you may answer, "Oh yes: the doctor was very clear about that, and she's always right. I should definitely take it with food." If I then ask, "Why must you take the medicine with food?" then you may answer, "I have no idea. The doctor didn't tell me." You know about one reason to take the medicine with food-the fact that the doctor told you to-but the question "Why must you take the medicine with food?" is, in this context, a request for a different kind of consideration: a medical consideration, the one that lies behind the doctor's instruction. When it comes to that reason, it is natural to say that you know you have the reason, but you do not know what it is. You know that you should take the medicine with food, but you do not know why.

Here is a more involved example. Imagine that you and I are at a crowded market. We are good friends, and you trust me to tell you the truth. We are separated, we both have cell phones, and we are avid texters-imagine. You receive a text from me, saying "Come and meet me at the top end of the market right away." You reply, "OK. Why?" I reply, "Just come quickly! You have a very strong reason to come to the top of the market right away!"

At this point, assuming that I am texting truly and sincerely and you are justified in trusting me, you know you have a strong reason to go to the top of the market as fast as you can: a reason, again, beyond the fact that you have just been told to go there by someone you trust. Yet, you do not know what the reason is. You do not even know what kind of reason it is. It could be a moral reason; perhaps someone is in danger and I need your help to save her. It could be a reason of self-interest; perhaps 
someone is giving away gifts at the top of the market, or perhaps I have seen a troublesome ex-partner of yours at the market and I am trying to help you avoid him. Or perhaps there is a beautiful sunset you will see from the top of the market, or perhaps someone you would like to meet is at the top of the market, or perhaps I am feeling panicky at the top of the market and need your immediate comfort. Any of these considerations would count as a reason for you to come to the top of the market, but they are all different kinds of reasons, and you cannot discriminate between them. All you know is that you should hurry to the top of the market, for some reason or other.

\section{FROM KNOWLEDGE OF REASONS TO FULLY SHAPED MOTIVES}

Think about the motives you will feel as you hurry through the market after receiving my text. Knowing that you have a good reason to get to the top of the market, you might move as fast as you can. But you will not find any determinate sense of urgency in your motives, because you will not know why you are acting. You are likely to feel a little bemused, alienated, or detached. Your rushing to the top of the market will not quite make sense to you. You will have a motive, but your ignorance about the nature of your reason will be reflected in your motive. As I will put it, your motive will not be "fully shaped."

Suppose that as you walk towards the top of the market, I continue to send you text messages. I tell you, "It's in your best interests to come to the top of the market straightaway!” Then, “There's a record for sale that you'll want to buy before anyone else gets their hands on it." Then, "It's by a seventies North American folk revival artist"; then, "It's a Gordon Lightfoot record"; then, "It's Sundown"; then, "It's an original mint condition US-issued LP"; then, "It's only \$2o"; then, "It has a yellow price sticker"; and finally, "The price sticker is on the top left-hand corner."

As you receive all this information, one piece at a time, you will gradually learn more about your reason to come to the top of the market as fast as you can. And as you learn more about your reason, your motive will become sharper. By the time you have received the last of my text messages, you will be fully engaged with your act of walking quickly towards the top of the market. You will fully understand what you are doing and why you are doing it. You will no longer be grasping for further information, needed to make your actions make sense. Your motive for walking to the top of the market will be fully shaped. 
As a motive comes closer to being fully shaped, in the sense in which I am interested, it does not necessarily get stronger. As you learn more about why you should hurry to the top of the market, your motivation may in fact get weaker, as various more urgent possibilities are excluded. Once you know that you will be buying a record, not helping me cope with a panic attack or saving a stranger from danger, you may judge that you have a weaker reason than you had suspected, and this may be reflected in your having a weaker motive.

To have a fully shaped motive, rather, is to have a motive whose quality is not open to change with further information about your circumstances-meaning information that fills out the details of your present situation, not information that reveals that the situation has changed. Your motive for hurrying to the top of the market is fully shaped once you have all the information you need in order to have a clear and complete sense of why your hurrying to the top of the market makes sense; it is fully shaped once further information becomes irrelevant. So, for example, it may be that you want to buy a copy of Sundown, and once you hear that a copy is for sale, that is enough for you to be fully motivated to go buy it. The record's time and place of issue, its price, and the color of its price sticker may be matters of indifference to you, so that learning about them makes no difference to your motive to get to the stall and buy the record.

(Further information may yet make a difference to your motives not by changing the quality of this motive, but instead by adding another, different motive. If you learn that the person working at the record store is a good friend of yours, trying to make a start in the used music business, then you may come to be even more strongly motivated to come to the stall and buy the record, as a way of supporting him in his new venture-but now because you have two different reasons, and two corresponding motives, not just one.)

We can learn something about what you take to be your reason for performing a certain action by seeing how your motive for performing the action varies with new information. If you need a certain piece of information before you can have a fully shaped motive, then that piece of information would seem to play a role in your reason for acting, as you see it. If a certain piece of information would make no difference to the quality of your motive, then it would seem not to be relevant to the reason you take yourself to have. One way to see what you take as your reason to act is to ask what information you need in order for your motive to act to be fully shaped.

Returning to the example: if you come to have a fully shaped motive once 
you hear that the record being sold at the top of the market is Gordon Lightfoot's Sundown-if the information beyond that makes no difference to the quality of your motive-then that suggests that you take it as your reason to rush to the top of the market that by doing so you will get a copy of Sundown. If, instead, you have a fully shaped motive once you hear that someone is selling a record by a North American folk revival artist - if it makes no difference to your motive to hear more about which artist or album it is-then that would suggest that your reason for rushing to the top of the market, as far as you are concerned, is just that you have the chance to buy a record by some North American folk revival artist or other. Alternatively, your motive might be fully shaped only once you hear that the record available is an original mint condition US-issued edition of Sundown, available for \$20; that would suggest that you take it as part of your reason that you can get this edition of the album at this cheap price. Or, conceivably, you may have made a bet with someone that you could find a copy of Sundown with a yellow price sticker in its top left corner; in that case, perhaps, you will take it as an essential part of your reason to buy the record that it has a yellow price sticker in its top left corner, and so you will not have a fully shaped motive for buying it until the news about the sticker comes through.

\section{KNOWLEDGE OF REASONS TO ASSIST}

Back, now, to moral reasons to help the global poor. What do we know about the plight of the global poor and our ability to help? Most of us are aware that there are many impoverished people in the world. We are aware that many people suffer hunger, disease, and exploitation, and that many people lack freedom and autonomy and cannot fulfill their most basic needs. We also know that we are able to make those people better off. We know, for example, that if we donate some money to Oxfam, then our money will be used to improve the lives of some people among the global poor.

Most of us do not know anything much, however, about the particular people who make up the global poor. Most of us are acquainted with only a few members of the global poor at most. Regarding the vast majority of individuals among the global poor, we do not know who they are, or exactly what plights they suffer, or exactly what they most need for their lives to be improved. When we give money to Oxfam we know it will be used to help some people, but we cannot name names. As a result, we are not equipped to feel any particularized concern for the individuals among the 
global poor. We are not able to have thoughts about particular poor people; when we think about helping the global poor, we are not able to think about anyone whom we are helping.

What do we then know about our reasons to help the global poor? The valuesbased principle of assistance and the individuals-based principle of assistance give different answers.

On the values-based principle of assistance, we would appear to know everything we need to know in order to have full knowledge of our moral reasons to help the global poor. We know that many people live in poverty, we know that the preconditions of autonomy are not met, we know that basic needs are not being fulfilled, we know that there is unhappiness and exploitation-we know all about the values at stake. We know, for example, that suffering is bad and that a donation to Oxfam will reduce suffering; if our reason to donate is a reason to reduce suffering, then in our present state of knowledge it is fully revealed.

On the individuals-based principle of assistance, however, we would appear to be in one of those situations in which we know we have a moral reason to act but do not know what the reason is. We know we have moral reasons to help the global poor. We know that there are many individuals in the world who demand our assistance, and whom we are able to assist. We know that for each of these individuals, we have a moral reason to help-but we do not know who those people are. We are not able to identify the individuals whose plights demand our assistance, so we are not able fully to identify our moral reasons to help them.

In light of the considerations discussed earlier, it follows that the values-based and individuals-based principles yield different predictions about our motives to help the global poor. On the values-based version, we can have fully shaped motives for helping the global poor. On the individuals-based version, we cannot. In being moved to help the global poor, on the individuals-based principle, we will lack a determinate sense of why our acts make sense. Particular individuals among the global poor are the sources of our moral reasons, but our motives do not have particular individuals on which to focus.

As mentioned earlier, most of us, many of us think, do not do as much as we should to help the global poor. There are many explanations of why this should be. We are selfish; we are weak-willed; we have other priorities; we feel helpless in the face of the problem of global poverty; we are ignorant, often willfully; we are tempted by claims that any contribution we might make will only make things worse; and so 
on (Singer 2009, ch. 4). There are also many explanations of why when we do help the global poor, we are more likely to be moved by particulars than by generalities. The general facts about global poverty are too big and complicated for us to comprehend; our emotions are engaged by personal stories, not by statistics; it is easier to forget a general fact than a personal story; personal stories reveal the suffering caused by global poverty in ways that general facts cannot; and so on. But the individuals-based principle of assistance, placed alongside some broad truths about how our knowledge of our reasons is reflected in our motives, offers a further explanation.

If the individuals-based principle of assistance is correct, then we need to know about particulars, not just generalities, in order to know exactly what moral reasons we have to help the global poor, as opposed to knowing merely that the reasons exist. Lacking such knowledge, it is unsurprising, in light of broader facts about motives and knowledge of reasons, that we should fail to do what we know we have reason to do. As we learn more about particular individuals among the global poor and the struggles they face, and as we imagine ourselves to be able to help particular identified impoverished people, it is predictable that we should feel more urgently gripped by our reasons to help and more likely to act on them.

It is not surprising, if the individuals-based principle of assistance is correct, that when we are faced only by the general facts about global poverty, we feel listless and unmotivated. We can see that moral reasons to help are there, but we feel removed from them, because we do not know exactly what they are. But we come into closer contact with those reasons, or at least feel that we do, when we are presented with more details about the plights of the global poor and of our ability to help: when we know about a particular disaster and the challenges it raises, when we are offered the chance to sponsor a particular child or development project, and when we are presented with detailed and personalized stories. So under such circumstances, goes the explanation, we are more likely to do something to help.

The explanation is not incompatible with other explanations of our habits of helping the global poor. It in fact fits nicely alongside them. Perhaps our emotions are more vividly engaged by particulars because we respond more vividly to our reasons the more we know about their nature. Perhaps we fall into weakness of will partly because our reasons to help the global poor are too distant to engage our motivations in the face of other temptations. 


\section{IN DEFENSE OF THE INDIVIDUALS-BASED PRINCIPLE OF ASSISTANCE: PART 1}

In offering this explanation of our motives to help the global poor, as so far expressed, we do not need to suppose that the individuals-based principle of assistance is correct. We need only suppose that most of us at some level take it to be correct. Our motives are informed not directly by our knowledge of our true reasons, but instead by our knowledge of the considerations that we take to be our reasons. (Even if you do not really have a reason to buy the copy of Sundown at the market, if you think you have such a reason, then that is enough to explain the quality of your motives as you receive the various pieces of information about its availability.) To put it another way, the explanation offered so far constitutes evidence that we take our moral reasons to help the global poor to be grounded in considerations of individuals, not of values-but still, we could be wrong.

That said, there is a good case for thinking that sometimes, at least, if we can show that we usually take a certain consideration as a reason, then we have strong evidence that it is in fact a reason. First, there is a case for being conservative, in a certain respect, in drawing conclusions about our reasons to help the global poor. Once we have accepted that we have moral reasons_-of one kind of another-for helping the global poor, and once we have seen that we treat certain considerations, rather than others, as our reasons, and when we do not have any cause to think that in taking those considerations as reasons we are making a mistake: well, at that point in the argument, it is most reasonable to be conservative, and to presume that the reasons we take ourselves to have are the reasons we really have.

Second, there are times at which we seem, in having certain motives, to be getting things right. To have a moral motive, sometimes, is to treat a given consideration as morally powerful. When you see a child who has fallen off her bike, and you find yourself motivated to go and help her, you do not experience your motive merely as an urge, but also as a perception of what would be an appropriate response to the situation. Where a moral motive appears to be correct, or appropriate, or called for, it has some authority. If it can be shown that to have that motive is to take a certain consideration as a reason, then we respect the authority of the motive by accepting, in the absence of any evidence to the contrary, that it is not deluded: that the consideration treated as a reason really is a reason (Keller 20I3, pp. 25-27, 84-87).

Coming to have a motive to help a member of the global poor upon learning 
about the details of her circumstances or to help a group of people upon learning that they are affected by a disaster is plausibly an experience that carries moral authority, in the relevant respect. It is not an experience of being emotionally manipulated or of coming to have a brute or alien urge. It is rather an experience of seeing more clearly why you should do more to help this person, or to help the people affected by this disaster. The motives generated appear to be appropriate and to count as proper responses to the situations. The motives carry authority, and so by learning more about the reasons that you posit in having those motives, we can learn more about what reasons are really there.

It seems to me, then, that the story told by the individuals-based principle of assistance-the story on which our motives to help the global poor are explained as responses to varying levels of knowledge about reasons grounded in considerations of individuals - should be accepted as a story about what reasons there are to help the global poor, not just about what reasons we think there are. The individualsbased principle of assistance then has a virtue that the values-based principle of assistance lacks. It is when we learn more about individuals, not when we learn more about values, that we learn more about our reasons for helping the global poor.

The explanation offered by the individuals-based principle of assistance is not a straightforwardly empirical explanation. It seeks to explain observed empirical phenomena, but it does so by employing a substantive normative claim (about the nature of reasons) plus a moral psychological claim (about the impact of our knowledge of reasons upon our motives). That said, the explanation is also not a moral explanation, if by that is meant a justification or excuse. When you know that you have a strong moral reason to perform a certain act, you should perform that act, even if you do not know what the reason is. When you know that there are many impoverished people who morally demand your assistance, you should render assistance, even if you do not know who those people are. The explanation does not show that we act rightly when we fail to act upon our reasons to assist the global poor. Instead, it places that failure within a broader, independently understandable phenomenon-one that has nothing specifically to do with global poverty, or indeed with morality. 


\section{IN DEFENSE OF THE INDIVIDUALS-BASED PRINCIPLE OF ASSISTANCE: PART 2}

If what I have said so far is correct, then the individuals-based principle of assistance tells an appealing story about our knowledge of our reasons to help the global poor and how that knowledge is reflected in our motives. The individualsbased principle of assistance is able to tell that story because it grounds our reasons to help the global poor in considerations of individuals, not of values. The principle of contribution, as mentioned earlier, is most naturally expressed as an individualsbased principle. On the individuals-based principle of contribution, our reasons to help the global poor are grounded in considerations of particular impoverished individuals to whose poverty the global rich have contributed. It may appear, then, that the individuals-based principle of contribution can offer a story just as attractive as the story told on the individuals-based principle of assistance.

For the individuals-based principle of contribution, the story would go like this. We can know that we have reasons to help the global poor just by knowing that many people are greatly impoverished and that we, the global rich, contribute to their poverty. Knowing that we have such reasons, however, is not the same as knowing what those reasons are. To have full knowledge of any of our reasons we need to know about the circumstances of particular individuals among the global poor, and we need to see how the poverty of those individuals, in particular, results from the acts of the global rich. Learning more about particulars of global poverty, and especially about our contribution to it, can then, on the principle of contribution, take us closer to full knowledge of our reasons to help the global poor. And that in turn can explain why learning more about particulars leads to our motives being more fully engaged, and why we are ultimately more likely to be moved by particulars than by generalities. The individuals-based principle of contribution, if this story succeeds, can do just as well as the individual-based principle of assistance.

The story told on the individuals-based principle of contribution is different in a small but significant respect from the story told on the individuals-based principle of assistance. On the individuals-based principle of assistance, you can know all about your reason to help a member of the global poor just by knowing about her poverty and your ability to help her. On the individuals-based principle of contribution, you also need to know that her poverty is partly due to the acts of the global rich. It is of course possible to learn that a person has suffered at the hands of the global 
rich, and possession of that information can add to the sense that something really must be done to help that person. That a person's poverty is caused by the acts of rich people can make her poverty all the more morally outrageous. Learning that the global rich have contributed to a person's poverty, however, is different from learning that you have contributed to her poverty-even if you are a member of the global rich.

You may find that a particular person's poverty results from the acts of the global rich. It is usually not possible, however, to find that her poverty results from any acts performed by you. You might find that the person's poverty is caused partly by the acts of certain rich governments and corporations and by global political forces that lead back to the global rich, but that is not to say that anything you have done has made any difference at all to her circumstances. That is not how these large global causal processes work. The global rich caused her poverty, and you are a member of the global rich, but it does not follow that you caused her poverty. Anything you have done, probably, is irrelevant.

As a result, there is a considerable distance between finding, following the principle of contribution, that the global rich ought to do something for an individual and finding that you ought to do something for that individual. You are one member of the global rich, but you cannot discharge an obligation on behalf of the entire global rich: not when the obligation is accrued in response to large-scale collective actions and forces. And it is possible for the global rich to discharge its obligation without you doing anything at all. Learning that someone's poverty is due to actions of the global rich might lead you to believe that the global rich have an obligation to provide restitution, but that is not to believe that her poverty is due to your actions or that you have any resultant obligation.

A similar relationship holds in the opposite direction. As a member of the global rich, you may be able to identify actions of yours that harm the global poor. Your habits of consumption, your use of energy, your support of various policies, governments, and corporations-all of these may count as acts that help reinforce global poverty. But to say that you harm the global poor is not to say that you harm any particular identifiable member of the global poor, and, probably, it is not possible even in principle to find any particular person who is worse off because of what you in particular have done. That, again, is not how the contribution of the global rich to the poverty of the global poor works.

None of this is to show that the principle of contribution is mistaken, or that we do not accrue obligations as a result of our individual contributions to acts that 
harm the global poor. The point is just that the story told on the principle of contribution cannot generate a direct moral relationship between a particular individual among the global poor and a particular individual among the global rich. Learning more about the circumstances of particular members of the global poor cannot pinpoint you as a person who has resultant reasons to help the global poor, arising from the contribution to global poverty made by the global rich. So when it comes to the phenomenon at issue - the power of knowledge of particulars in forming our patterns of motivation to help the global poor-the individuals-based principle of contribution cannot adopt the explanation offered on behalf of the individuals-based principle of assistance. Considerations of our motives in responding to global poverty ground an argument for the individuals-based principle of assistance, but not for the individuals-based principle of contribution.

\section{CONCLUSION}

I have tried to articulate and make plausible a principle that explains why we, as members of the global rich, have reason to help the global poor. The principle is the individuals-based principle of assistance: it says that we should help the global poor because we can, and at little sacrifice, and it grounds this claim in considerations of the particular individual persons among the global poor who would benefit from our help. It depicts our moral reasons to help the global poor as reasons that fall upon each of us considered separately, and that take individual members of the global poor separately as their objects.

My case for the principle is that it yields a plausible story about what we know about our reasons to help the global poor and about how our knowledge of our reasons is reflected in our motives. You are most likely to be moved to help a person in need when you are vividly aware of the person's needs and of a course of action by which you could help ensure that those needs are met. On the story I tell, this fact about our motivations is not merely psychological, but emerges predictably from the structure of our reasons and our ability to have knowledge of our reasons. Placed alongside some general truths about how our motivations are engaged by knowledge about our reasons, the individuals-based principle of assistance can explain why our motivations to help the global poor are most pointed and powerful when we are confronted with facts about particular people and particular circumstances.

The individuals-based principle of assistance can be distinguished from the 
values-based principle of assistance and from the principle of contribution, and it is the only one of those principles, I have tried to show, that can tell the plausible story identified. It follows that the individuals-based principle of assistance gives the best explanation of the reasons held by individuals among the global rich to give help to the global poor. To that extent, there is good reason to accept the individuals-based principle of assistance as correct and indispensable.

It does not follow, however, that alternative principles are incorrect. There are other questions to be asked about reasons to help the global poor, apart from the question of what we as individuals among the global rich should be doing. Among them are the questions of what reasons the governments of rich countries have to help the global poor, and what corporations and other rich institutions should do, and how the arrangement of global institutions should be changed in response to the plight of the global poor. These are questions about what should be done by collective agents and institutions. Regarding these questions, perhaps, the principle of contribution is more plausible, as it can focus upon the contribution to global poverty made by larger entities and forces, and upon the global poor considered as a class.

Let me emphasize in closing that the story I have told about our reasons to help the global poor is not intended to show that our reasons are not as strong as we might have thought, or that they only become powerful when we happen to be faced by knowledge of particulars. When we confront our obligations to the global poor, we find ourselves in an epistemic situation that involves a certain kind of motivational barrier. Most of us, most of the time, know that we have reasons to assist the global poor, but we do not know what those reasons are, exactly; and it is a general truth that mere knowledge of the existence of a reason is not as motivationally gripping as is knowledge of the nature of that reason. That barrier appears to be a real and consequential barrier-by positing the existence of the barrier, we can explain something about how and when people come to be motivated to do things that help the global poor-and in recognizing it, perhaps we can come better to see why it should and could be overcome.

Acknowledgements: I am grateful for helpful comments from Nick Agar, Christian Barry, Garrett Cullity, Ramon Das, Ole Koksvik, Gerhard Overland, Vanessa Schouten, Dan Weijers, and two anonymous referees. 


\section{REFERENCES}

ASHFORD, E., 2007. The Duties Imposed by the Human Right to Basic Necessities. In: T. Pogge, ed. Freedom from Poverty as a Human Right. Oxford: Oxford University Press, 183-218.

BARRY, C. and OVERLAND, G., 20r2. Are Trade Subsidies and Tariffs Killing the Global Poor? Social Research 79 (4), 865-896.

2013. How Much for the Child? Ethical Theory and Moral Practice, I6 (I), I89-204.

CULLITY, G., 2004. The Moral Demands of Affluence. Oxford: Oxford University Press.

KELLER, S., 2013. Partiality. Princeton: Princeton University Press.

KYMLICKA, W., 2002. Contemporary Political Philosophy 2nd ed. Oxford: Oxford University Press.

O'NEILL, O., 2007. Kantian Approaches to Some Famine Problems. In: R. Shafer-Landau, ed. Ethical Theory: An Anthology. Malden, MA: Blackwell, 553-564.

POGGE, T., 2002. World Poverty and Human Rights. Cambridge: Polity.

2007. Eradicating Systematic Poverty: Brief for a Global Resources Dividend. In: H. LaFollette, ed. Ethics in Practice 3rd ed. Malden, MA: Blackwell, 633-646.

20Io. Politics as Usual. Cambridge: Polity.

RAWLS, J., 1972. A Theory of Justice. Oxford: Clarendon Press.

RISSE, M., 2012. Global Political Philosophy. Basingstoke: Palgrave Macmillan.

SHAH, A., 2oIr, Poverty Around the World [online]. Available from: http://www.globalissues.org/ article/4/poverty-around-the-world\#WorldBanksPovertyEstimatesRevised [Accessed 8 June 2015].

ORGANISATION FOR ECONOMIC CO-OPERATION AND DEVELOPMENT, 2015. Development aid stable in 2014 but flows to poorest countries still falling [online]. Available from: http:// www.oecd.org/dac/stats/development-aid-stable-in-20r4-but-flows-to-poorest-countries-still-falling. htm [Accessed 8 June 20I5].

SINGER, P., 1972. Famine, Affluence and Morality. Philosophy and Public Affairs I (3), 229-243.

2009. The Life You Can Save. Melbourne: Text Publishing. 